\title{
Asiatic acid prevents the development of interstitial lung disease in a hypochlorous acid-induced mouse model of scleroderma
}

\author{
XIAORU XIA $^{1^{*}}$, CAIJUN DAI $^{2 *}$, HUA YU $^{3}$, XIAOYING HUANG $^{4}$, ALI CHEN $^{4}$, \\ YINGXIA TAN $^{5}$ and LIANGXING WANG ${ }^{4}$
}

\author{
${ }^{1}$ Department of Rheumatology, The First Affiliated Hospital of Wenzhou Medical University, Wenzhou, Zhejiang 325000; \\ ${ }^{2}$ Department of Respiratory Medicine, Jinhua Municipal Central Hospital, Zhejiang University Jinhua Hospital, Jinhua, \\ Zhejiang 321000; Departments of ${ }^{3}$ Geriatric Medicine and ${ }^{4}$ Pulmonary Medicine; ${ }^{5}$ Central Laboratory, \\ The First Affiliated Hospital of Wenzhou Medical University, Wenzhou, Zhejiang 325000, P.R. China
}

Received September 3, 2017; Accepted February 15, 2018

DOI: $10.3892 / \mathrm{ol} .2018 .8412$

\begin{abstract}
Interstitial lung disease is the most common complication of systemic sclerosis ( $\mathrm{SSc}$ ) and is associated with a high rate of mortality. Due to the complex pathogenesis of SSc, the therapies currently available remain limited. In the present study, the effect of asiatic acid (AA) on SSc-associated pulmonary fibrosis $(\mathrm{PF})$ and its association with the transforming growth factor- $\beta 1$ (TGF- $\beta 1) /$ Smad $2 / 3$ signaling pathway were evaluated. A hypochlorous acid ( $\mathrm{HOCl})$-induced model of $\mathrm{SSc}$ was used to evaluate the therapeutic effect of AA on PF in SSc, where AA was administered to SSc mice by gavage. PF was alleviated in the AA-treated SSc mice groups when examined under light microscopy. In addition, there was a decrease in histopathological progression and collagen in the lungs. AA significantly reduced expression of type I collagen in the lungs of mice with SSc. It also significantly suppressed $\alpha$-smooth muscle actin expression, which attenuated the conversion of fibroblasts into muscle fibroblasts. These AA-associated antifibrosis and anti-immune effects were mediated through the significant downregulation of advanced oxidation protein product, E-selectin, and anti-DNA topoisomerase-1 autoantibody levels in the serum. Furthermore, the expression levels of TGF- $\beta 1$ and the phosphorylated-Smad2/3/Smad $2 / 3$ ratios in AA-treated SSc mice were similar to the control. The presence
\end{abstract}

Correspondence to: Professor Liangxing Wang, Department of Pulmonary Medicine, The First Affiliated Hospital of Wenzhou Medical University, Nangbaixiang, Wenzhou, Zhejiang 325000, P.R. China

E-mail:wzyxywlx@163.com

Dr Yingxia Tan, Central Laboratory, The First Affiliated Hospital of Wenzhou Medical University, Nangbaixiang, Wenzhou, Zhejiang 325000, P.R. China

E-mail: tanyingxia2005@aliyun.com

${ }^{*}$ Contributed equally

Key words: scleroderma, interstitial lung disease, asiatic acid, hypochlorous acid, tumor growth factor- $\beta 1 / \mathrm{Smad} 2 / 3$ signaling pathway of pulmonary inflammation and fibrosis was confirmed in the HOCl-induced SSc mice and the results demonstrated that selective inhibition of reactive oxygen species prevented $\mathrm{PF}$. By focusing on the classical TGF- $\beta 1 / \mathrm{Smad} 2 / 3$ signaling pathway, a mechanism of action of AA was identified to be associated with the inhibition of Smad2/3 activation through negative regulation of Smad2/3 phosphorylation.

\section{Introduction}

Systemic sclerosis (SSc), also known as scleroderma, is a multisystem connective tissue disease, and its pathogenesis is associated with several factors, including inflammation, autoimmune antibodies, extensive fibrosis and microvascular changes (1). This disease may lead to life-threatening complications, including pulmonary hypertension and interstitial lung disease (ILD) (2). The roles of the oxidative stress pathways in SSc pathogenesis have been explored in previously. Bourji et al (3) reported reactive oxygen species (ROS) may be involved in early skin fibrogenesis. Constitutive intracellular production of ROS is essential for fibroblast proliferation and expression of type I collagen (Col-I) in SSc cells (4-6). Furthermore, the development of fibrosis involves a detrimental cycle between transforming growth factor- $\beta 1$ (TGF- $\beta 1$ ) and ROS (7). Emerging evidence indicates that ROS stimulates fibrosis through modulation of the TGF- $\beta 1 / \mathrm{Smad} 2 / 3$ signaling pathway $(8,9)$. Similar to resident epithelial cells and fibroblasts, TGF- $\beta 1$ drives fibrocytes to differentiate into myofibroblasts through activation of the Smad2/3, stress-activated protein kinase/JUN N-terminal kinase, and mitogen-activated protein kinase signaling pathways, which stimulate $\alpha$-smooth muscle actin ( $\alpha$-SMA) expression $(10,11)$. Due to the complex pathogenesis of SSc, the availability of effective therapies to treat this disease is currently limited.

Asiatic acid (AA) is a triterpenoid extracted from Centella asiatica (12) with a variety of protective properties, including against inflammation (13), oxidation (14), and fibrosis $(15,16)$. Furthermore, AA reduces islet fibrosis, suppresses mitochondria-mediated inflammasome activation, ameliorates hepatic lipid accumulation and insulin resistance, and reduces infarct volume following focal cerebral ischemia (3,17-19). Previous studies have demonstrated AA alleviates cardiovascular 
remodeling in hypertensive rats and protects against diabetic cardiomyopathy (4,5). In addition, AA may inhibit liver and renal tuberlointersitial fibrosis $(12,20)$, and bleomycin -induced pulmonary fibrosis (PF) (21).

Overall, it is essential to characterize the pathogenesis of SSc and associated interstitial pneumonia, as well as identify a fibrosis-inhibiting drug that is therapeutically effective with few side effects. In the present study, whether AA ameliorates $\mathrm{PF}$, and modulates myofibroblast differentiation, immune dysfunction and oxidative stress was determined. In addition, it was determined whether any of these effects are mediated through the classical TGF- $\beta 1 / \mathrm{Smad} 2 / 3$ signaling pathway.

\section{Materials and methods}

Animals. A total of 40, six-week-old female-specific pathogen-free BALB/c mice with a mean weight of $25 \mathrm{~g}$ were housed at the Experimental Animal Center at Wenzhou Medical University (Zhejiang, China) at $20-24^{\circ} \mathrm{C}$ with $40-60 \%$ humidity and with a regular light-dark cycle. The animals were allowed free access to water and standard mouse chow. The present study was approved by the Institutional Animal Care and Use Committee of Wenzhou Medical University. Efforts were made to minimize animal suffering and the number of animals used in experiments.

Reagents. Sodium hypochlorite $(\mathrm{NaClO})$, potassium dihydrogen phosphate $\left(\mathrm{KH}_{2} \mathrm{PO}_{4}\right)$ solution, sodium carboxymethylcellulose (CMC-Na) and AA were obtained from Sigma-Aldrich; Merck KGaA (Darmstadt, Germany). AA was dissolved in dimethyl sulfoxide, and then diluted with a $0.5 \% \mathrm{CMC}$-Na solution to create separate solutions with concentrations of 0.1 and $0.4 \mathrm{mg} / \mathrm{ml}$. Advanced oxidation protein products (AOPP; 10572-09m), E-selectin (E-sel; 10316-09m) and anti-DNA topoisomerase I autoantibody (TOP1-Ab; 10821-09m) enzyme-linked immunosorbent assay (ELISA) kits were obtained from Shanghai Boyun Biochemical Institute (Shanghai, China; http://www.chem-china. net/). Rabbit antibodies against type I collagen (Col-I; ab21286) and $\alpha$-SMA (ab5694), and mouse antibodies against TGF- $\beta 1$ (ab64715) were purchased from Abcam (Cambridge, UK). Rabbit antibodies against GAPDH (cat. no. 8884), Smad2/3 (cat. no. 8685), and phosphorylated (p)-Smad2/3 (cat. no. 8828) were purchased from Cell Signaling Technology Inc., (Danvers, MA, USA). Goat anti-rabbit (BA1054) and goat anti-mouse horseradish peroxidase (HRP)-conjugated IgG (BA1050) were purchased from Wuhan Boster Biological Technology, Ltd. (Wuhan, China). A DAB kit and mouse/rabbit plus Polymer HRP Detection system (PV-6000) were provided by OriGene Technologies, Inc. (Beijing, China). SuperSignal West Femto Maximum Sensitivity substrate and a BCA Protein Assay kit were obtained from Thermo Fisher Scientific, Inc. (Waltham, MA, USA). RIPA lysis buffer was obtained from Beyotime Institute of Biotechonology (Shanghai, China).

Generation of $\mathrm{HOCl}$. $\mathrm{HOCl}$ was synthesized by adding $166 \mu \mathrm{l}$ $\mathrm{NaClO}$ solution (2.6\% active chlorine) to $11.1 \mathrm{ml} \mathrm{K \textrm {K } _ { 2 }} \mathrm{PO}_{4}$ solution (100 mM; pH 7.2) as previously described (22). The $\mathrm{HOCl}$ concentration was measured using a spectrophotometer at wavelength $292 \mathrm{~nm}$ (molar absorption coefficient, $\left.350 \mathrm{M}^{-1} \mathrm{~cm}^{-1}\right)$.
Experimental groups and treatments. The mice were randomly divided into control, model, treatment with a low dose of AA of $2 \mathrm{mg} / \mathrm{kg} /$ day (LAA), and treatment with a high dose of AA of $8 \mathrm{mg} / \mathrm{kg} /$ day (HAA) groups ( $\mathrm{n}=10 \mathrm{mice} /$ group). AA was dissolved in a $0.5 \% \mathrm{CMC}-\mathrm{Na}$ solution to create separate solutions with concentrations of 0.1 and $0.4 \mathrm{mg} / \mathrm{ml}$. Mice in the model group received $300 \mu \mathrm{HOCl}$ subcutaneously and $0.5 \% \mathrm{CMC}-\mathrm{Na}$ solution by gavage every day for 6 weeks, while mice in the control group received $300 \mu 1$ sterilized PBS subcutaneously and $0.5 \%$ CMC-Na solution orally every day for 6 weeks. Mice in the LAA and HAA groups received $0.5 \mathrm{ml}$ AA solution ( 2 and $8 \mathrm{mg} / \mathrm{kg} / \mathrm{day}$, respectively) by gavage, as well as received $\mathrm{HOCl}$ injections as aforementioned for the model group.

Two weeks after treatment was halted, the mice were sacrificed, and their lungs and serum harvested.Lower right lung lobe samples were washed with cold PBS, fixed in $4 \%$ buffered paraformaldehyde at $4^{\circ} \mathrm{C}$ for $24 \mathrm{~h}$, and then embedded in paraffin for histological and immunohistochemical studies. The remaining lung tissue was snap-frozen in liquid nitrogen and stored at $-80^{\circ} \mathrm{C}$ until processed for protein extraction. Expression of AOPP, E-sel, and TOP1-Ab was measured in the collected mouse serum.

Histopathological and immunohistochemical staining. The lower right lobes of the collected lungs were fixed in $4 \%$ paraformaldehyde at $4^{\circ} \mathrm{C}$ overnight, dehydrated in a graded ethanol series, embedded in paraffin, and then sectioned into $5-\mu \mathrm{m}$ thick slices. Histopathological changes were assessed using hematoxylin and eosin (H\&E) staining. Tissue sections were deparaffinized in xylene and hydrated gradually through graded alcohol series and processed with PBS buffer solution. Hematoxylin was applied for $3 \mathrm{~min}$ in room temperature, and then rinsed in $\mathrm{H}_{2} \mathrm{O}$ for $5 \mathrm{~min}$. Eosin was used for staining for $1 \mathrm{~min}$ in room temperature, and then $\mathrm{H}_{2} \mathrm{O}$ for $1 \mathrm{~min}$. The sections were dehydrated with an ascending alcohol series (75, 85,95 and $100 \%$ ) for 3 min each, and then xylene was used twice for 3 min each. Another set of sections was stained to visualize interstitial collagen using Masson's trichrome method (23). Primary antibodies against $\alpha$-SMA and Col-I were diluted 1:300 in PBS. Tissue were treated with $3 \%$ hydrogen peroxide at $37^{\circ} \mathrm{C}$ for $10 \mathrm{~min}$, and high pressure cooker, $>120^{\circ} \mathrm{C}$ for $10 \mathrm{~min}$. Primary antibodies against $\alpha$-SMA and Col-I were used and kept overnight at $4^{\circ} \mathrm{C}$. After washing with PBS, then incubated with the secondary antibody of PV-6000 at $37^{\circ} \mathrm{C}$ for $20 \mathrm{~min}$, and then dyed with DAB developer of PV-6000. The sections were dehydrated by graded alcohol for $5 \mathrm{~min}$ each, and then washed in xylene twice for $3 \mathrm{~min}$. Pulmonary histopathological changes and areas that stained positive were observed by light microscopy. Five random, non-overlapping, high-power (original magnification, $\mathrm{x} 400$ ) fields were evaluated on each slide. The integrated optical density of positively stained cells was measured using Image-ProPlus 6.0 (Media Cybernetics, Inc., Rockville, MD, USA).

Cytokine assays. Expression levels of AOPP, E-sel and TOP1-Ab in serum were measured using the relevant ELISA kits according to the manufacturer's protocol. A total of $50 \mu \mathrm{l}$ of each standard and sample were added into the appropriate well. $10 \mu \mathrm{l}$ Biotinylated antibodies to AOPP and E-sel, and 


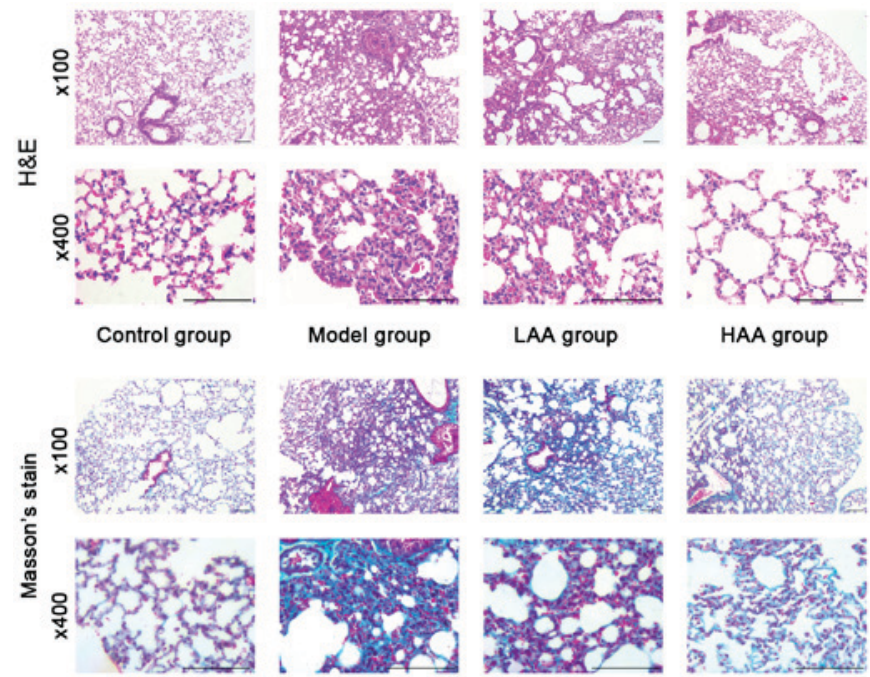

Figure 1. Histological evaluation of mouse lungs. Representative pathological findings from lungs from each cohort stained with H\&E and Massome's trichrome at $\mathrm{x} 100$ (top line) and $\mathrm{x} 400$ (bottom line) magnification. Scale bar, $100 \mu \mathrm{m}$. H\&E, hematoxylin and eosin; AA, asiatic acid; LAA, low dose of AA ( $2 \mathrm{mg} / \mathrm{kg} /$ day); HAA, high dose of AA ( $8 \mathrm{mg} / \mathrm{kg} /$ day).

antigen to TOP1 were coated to samples separately. $50 \mu 1$ chain enzyme avidin-HRP was added and incubated at $37^{\circ} \mathrm{C}$ for $60 \mathrm{~min}$, followed by washing four times with washing buffer (provided in the kit) for $30 \mathrm{sec}$. Developer $(100 \mu \mathrm{l})$ was added and kept in the dark at $37^{\circ} \mathrm{C}$ for $10 \mathrm{~min}$. The stop solution $(50 \mu \mathrm{l})$ was added to each well to terminate the reaction. The optical density of each sample was read at $450 \mathrm{~nm}$. The results were calculated using the linear regression equation based on the standard curve.

Western blot analysis. The lungs were homogenized in RIPA lysis buffer containing phenylmethylsulfonyl fluoride (PMSF) (RIPA: PMSF 100:1) and then centrifuged at 15,000 x g for $30 \mathrm{~min}$ at $4^{\circ} \mathrm{C}$. The resulting supernatants were collected and determined using the BCA protein assay. Subsequently, $20 \mu \mathrm{g}$ of protein/lane was separated using 10\% SDS-PAGE and then transferred onto polyvinylidene difluoride membranes. The membranes were then blocked at room temperature for $1 \mathrm{~h}$ with $5 \%$ milk and incubated overnight at $4{ }^{\circ} \mathrm{C}$ with primary antibodies against TGF- $\beta 1$ (1:500), Smad2/3, and p-Smad2/3 (1:500) and GAPDH (1:500). Subsequently, the membranes were incubated with the relevant HRP conjugated secondary antibody (goat anti-rabbit IgG for GAPDH, 1:10,000; goat anti-mouse $\mathrm{IgG}$ for the other primary antibodies, 1:10,000) at room temperature for $1 \mathrm{~h}$ and then developed using Clarity Western ECL Substrate (cat. no. 1705060; Bio-Rad Laboratories, Hercules, CA, USA). Images were collected and analyzed using the Image Lab program 5.0 (Bio-Rad Laboratories, Inc., Hercules, CA, USA).

Statistical analysis. Data are expressed as the mean \pm standard deviation. All calculations were performed using SPSS version 19.0 (IBM Corp., Armonk, NY, USA). Differences between groups were identified by one-way analysis of variance (ANOVA) with post hoc contrasts by Student-Newman-Keuls test. $\mathrm{P}<0.05$ was considered statistically significant.

\section{Results}

Effect of AA on pulmonary interstitial fibrosis in vivo. In the model group, the lungs were pale and stiff, and were harder compared with lungs from the control group following treatment for 6 weeks with $\mathrm{HOCl}$ (Fig. 1). In addition, amongst the groups treated with AA, the LAA and HAA groups had softer and more flexible lungs compared with the model group, indicating elasticity was rescued in these lungs. The effect of AA on remodeling of the lung tissue in SSc mice was assessed based on histopathological examination. Lungs in the model group exhibited thickening of their alveolar walls, broadening of their septum and infiltration of inflammatory cells as shown in Fig. 1. However, this inflammation was not observed in either the LAA or HAA groups. Based on Masson's stain, there was also less collagen fiber deposition in the lungs of AA-treated mice. Furthermore, the lung structure in the HAA group was more similar to normal lungs compared with the model group.

AA affects $\alpha$-SMA and Col-I expression. The therapeutic antifibrotic effects of AA on lung pathology was assessed in a $\mathrm{HOCl}$-induced SSc mouse model. Immunohistochemical staining was used to evaluate $\alpha$-SMA and Col-I expression in lungs prior to and following AA treatment (Fig. 2). The expression of $\alpha$-SMA and Col-I was significantly reduced in the lungs following AA treatment compared with the model group. Compared with the control group, the expression levels of both proteins were significantly higher in the model group $(\mathrm{P}<0.05)$. Compared with the model group, the expression levels of both proteins were significantly lower in the HAA group $(\mathrm{P}<0.05)$. Notably, $\alpha$-SMA expression in the HAA group was significantly lower compared with that of the LAA group $(\mathrm{P}<0.05)$. No significant difference was identified in Col-I expression between the LAA and HAA groups, but a decreasing trend was observed.

Effect of AA on AOPP, E-sel, and TOPI-Ab concentrations. To evaluate the effects of AA on oxidative stress, damage to the epithelium and vessels, and immune response, AOPP, E-sel and TOPI-Ab expression was evaluated in serum from the mice (Fig. 3A-C). Compared with the control group, AOPP, E-sel and TOPI-Ab levels were significantly higher in the model group $(\mathrm{P}<0.05)$. In addition, all three expression levels were significantly lower in the HAA group compared with the model group $(\mathrm{P}<0.05)$. Expression of E-sel and TOPI-Ab was significantly lower in the HAA group compared with the LAA group $(\mathrm{P}<0.05)$. No significant difference in E-sel and TOPI-Ab levels were identified between the LAA and model group.

Effect of AA on TGF- $\beta 1$ and $p$-Smad2/3/Smad2/3 expression. To identify the potential mechanism underlying the effect on AA treatment of mice with SSc and SSc-associated ILD, TGF- $\beta 1 / \mathrm{Smad} 2 / 3$ signaling way was examined by measuring TGF- $\beta 1$ expression (Fig. 3D) and $\mathrm{p}-\mathrm{Smad} 2 / 3 / \mathrm{Smad} 2 / 3$ ratios (Fig. 3E). A higher expression level of TGF- $\beta 1$ and higher $\mathrm{p}-\mathrm{Smad} 2 / 3 / \mathrm{Smad} 2 / 3$ ratios were identified in the model group compared with the control $(\mathrm{P}<0.05)$. Expression of TGF- $\beta 1$ was significantly decreased in the HAA groups compared with the model group $(\mathrm{P}<0.05)$, as well as significantly different between the LAA and HAA groups $(\mathrm{P}<0.05)$. 
A

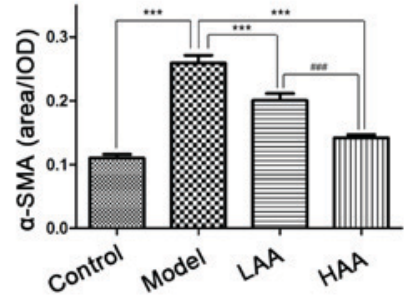

C
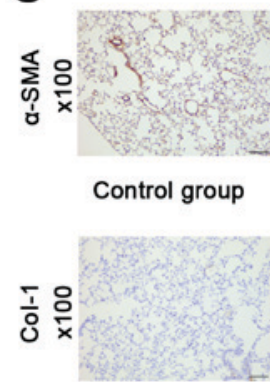

B
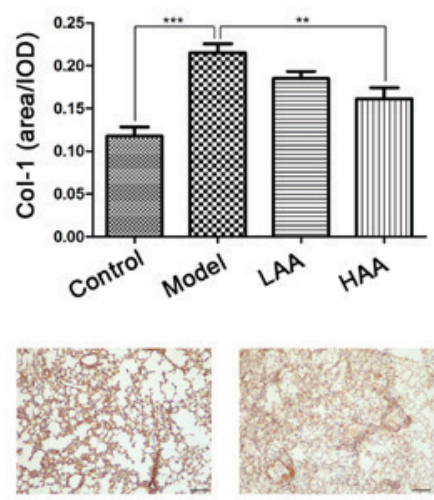

LAA group

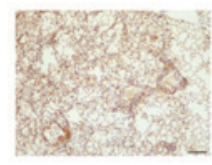

HAA group
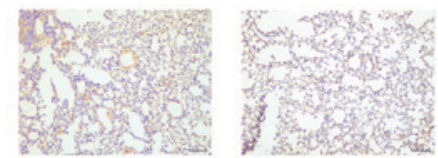

Figure 2. Effect of AA on $\alpha$-SMA and Col-I expression in SSc and normal lungs. The effect of AA on (A) $\alpha$-SMA and (B) Col-I expression in each mouse group. (C) Immunohistochemical staining was used to evaluate $\alpha$-SMA and Col-I expression in mouse lungs. Images are presented at magnification, $\mathrm{x} 100$. ${ }^{* *} \mathrm{P}<0.01$, and ${ }^{* * *} \mathrm{P}<0.001$, compared with the model group. ${ }^{\# \# \#} \mathrm{P}<0.001$, compared with the LAA group. Image-ProPlus software was used to calculate the relative expression levels. Scale bar, $100 \mu \mathrm{m}$. AA, asiatic acid; LAA, low dose of AA ( $2 \mathrm{mg} / \mathrm{kg} /$ day); HAA, high dose of AA ( $8 \mathrm{mg} / \mathrm{kg} / \mathrm{day}) ; \alpha$-SMA, $\alpha$-smooth muscle actin; Col-I, type I collagen; OD, optical density.

A

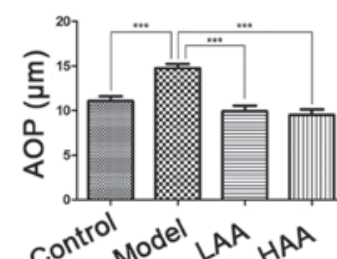

D
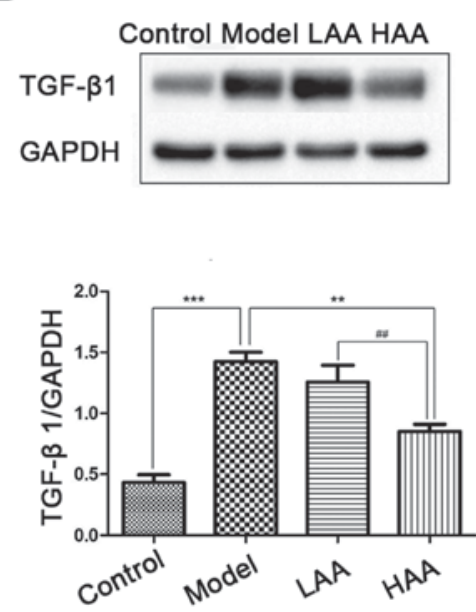

C

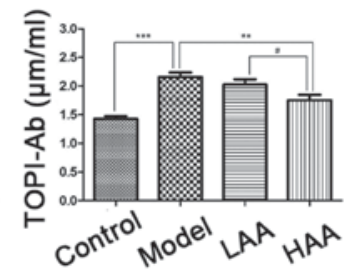

$\mathrm{E}$
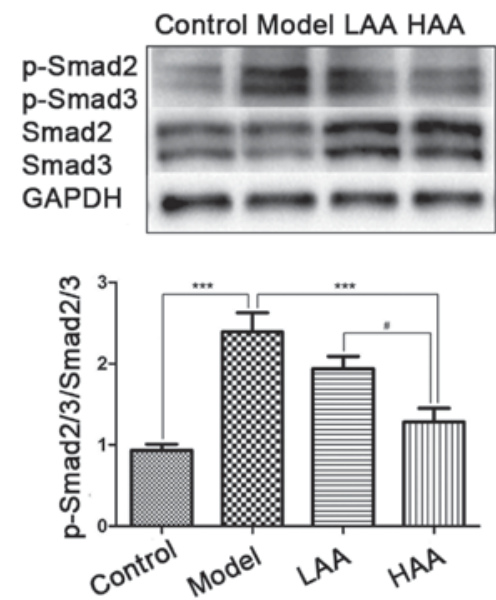

Figure 3. Effect of AA on AOPP, E-Sel, TOP1-Ab, TGF- $\beta 1$ and p-Smad2/3 expression levels. Effects of AA on (A) AOPP, (B) E-Sel and (C) TOP1-Ab levels in mouse serum. (D) TGF- $\beta 1$ and (E) $\mathrm{p}-\mathrm{Smad} 2 / 3 / \mathrm{Smad} 2 / 3$ levels were measured by western blotting. ${ }^{* *} \mathrm{P}<0.01$, and ${ }^{* * * *} \mathrm{P}<0.001$, compared with the model group. ${ }^{\#} \mathrm{P}<0.05,{ }^{\# \#} \mathrm{P}<0.01$, and ${ }^{\# \# \#} \mathrm{P}<0.001$, compared with the LAA group. AA, asiatic acid; LAA, low dose of AA (2 mg/kg/day); HAA, high dose of AA (8 mg/kg/day); TGF- $\beta 1$, tumor growth factor- $\beta 1$; p-, phosphorylated; AOPP, advanced oxidation protein products; E-sel, E-selectin; TOP1-Ab, anti-DNA topoisomerase I autoantibody.

\section{Discussion}

SSc is a multisystem disease with a variable clinical course (1).
Its prognosis is typically poor, corresponding with the extent of microangiopathy, and fibrosis of skin and internal organs (1). Although SSc pathogenesis is associated with fibroblast 
disorder and leads to multi-organ or systemic changes, the specific mechanisms underlying this disease have not been well characterized, and there is still a lack of efficacious chemical treatments.

It was previously demonstrated that ROS serve an essential role in SSc-associated ILD pathogenesis (24). Overproduction of ROS, induced by fibroblasts and endothelial cells, stimulate inflammatory reactions, oxidization of DNA topoisomerase-I and overexpression of AOPP (25). The high amounts of AOPP generated by agents induced by $\mathrm{HOCl}$ in the skin spread the fibrosis from skin to tissues via systemic circulation, and result in SSc-associated ILD and TOPI-Ab $(25,26)$. The overexpression of DNA topoisomerase-I induces hydrogen peroxide production by endothelial cells, and fibroblast proliferation (25). Furthermore, oxidative stress leads to $\mathrm{T}$ cell infiltration in the lung fibrosis (27). In the present study, ROS administered in the form of subcutaneously injected $\mathrm{HOCl}$ was used to induce SSc in a mouse model that has been widely used since 2009 (22). Preliminary experiments in SSc mice were also performed by assessing the effects of different doses of $\mathrm{HOCl}$ as described previously (7,20,28-30), $300 \mu 1$ was chosen as the optimal dose. This model mimicked the diffuse cutaneous form of human SSc, which exhibited increased collagen deposition, inflammatory infiltration in the lungs and autoimmune activation compared with control mice. Using this mouse model, the therapeutic efficacy of AA for SSc was assessed.

TGF- $\beta$ is the most potent profibrogenic cytokine and its expression is increased in almost all fibrotic diseases (31). TGF- $\beta 1$, a member of the TGF superfamily, is a potent profibrotic factor that induces collagen synthesis and has been well studied in fibrogenesis (12). It has been demonstrated to serve an important role in pulmonary fibrosis and airway remodeling $(32,33)$. Excessive activation of TGF- $\beta 1$ induces the phosphorylation of Smad2 and Smad3, subsequently forming a novel complex on the nuclear membrane (34). Phosphorylation of receptor-regulated SMADs, in particular Smad $2 / 3$ following TGF- $\beta 1$ activation, binds to TGF- $\beta$ type I and II receptors, and activates the TGF- $\beta 1 / \mathrm{Smad} 2 / 3$ signaling pathway $(8,9)$. Mesenchymal transition through the activation of TGF- $\beta 1 / \mathrm{Smad} 2 / 3$ signaling pathway may stimulate myofibroblast proliferation and fibroblast conversion to myofibroblast (35). The current study observed significantly high expression of TGF- $\beta 1$ and high $\mathrm{pSmad} 2 / 3 / \mathrm{Smad} 2 / 3$ ratios in the $\mathrm{HOCl}$-induced $\mathrm{SSc}$ mouse model compared with the control group. A study by $\mathrm{Xu}$ et al (11) delineated an underlying mechanism of lung fibrosis in which epithelial and mesenchymal cells are activated by TGF- $\beta 1 / \mathrm{Smad} 2 / 3$ signaling through $\mathrm{Wnt}$ and $\beta$-catenin activation.

AA reduces the occupancy of Smad2/3 elements in response to TGF- $\beta$. Previous studies have reported that AA treatment inhibits TGF- $\beta 1$ and Smad2/3 expression in cardiac hypertrophy, and liver and renal interstitial fibrosis $(12,14-16,20)$. It was demonstrated AA suppresses TGF- $\beta /$ Smad signaling in tissue fibrosis and may be an effective candidate for treatment of acute injury associated with pulmonary fibrosis (21). To the best of our knowledge, the present study demonstrated for the first time that high concentrations of AA may inhibit the phosphorylation of $\mathrm{Smad} 2 / 3$ by reducing TGF- $\beta 1$ in $\mathrm{SSc}$-associated $\mathrm{PF}$ induced by $\mathrm{HOCl}$. Based on the data in the current study, in combination with a report by Dong et al (21), AA-induced inhibition of SSc-associated PF may be mediated, at least in part, through the TGF- $\beta / \mathrm{Smad} 2 / 3$ signaling pathway. Autoimmune antibodies, including TOP1-Ab, are produced for self-protection (18). E-sel is also released when cell damage occurs $(13,14)$. This was also observed in the serum of SSc mice. A previous study demonstrated that serum E-sel level was positively associated with the presence and extent of pulmonary fibrosis (36). In addition, during the early stage of SSc, activated fibrosis produces abundant ROS, which stimulates Col-I expression and leads to fibrosis (25). The inhibition of the development of mouse SSc-ILD by AA may explain the decreased expressions of circulating oxidized proteins in the sera, and especially TOP1-Ab, E-sel and depression in the concentration of Col-I in the lung of treated animals. Therefore, we hypothesize the release of highly toxic ROS by activated fibroblasts and endothelial cells induce inflammation that triggers the recruitment of inflammatory cells, the production of cytokines, and increases fibrosis.

In conclusion, the results of the present study confirmed the presence of pulmonary inflammation and fibrosis in a murine model of HOCl-induced SSc, and demonstrated that selective inhibition of ROS reduces PF in this model. By focusing on the classical TGF- $\beta 1 / \mathrm{Smad} 2 / 3$ signaling pathway, it was observed that AA significantly inhibited the phosphorylation and, thus, the activation of Smad2/3. This phenotype was even more significant when high concentrations of AA were used. This pathway may be one of the most important ways in which AA affects SSc-associated ILD. A drug similar to AA that regulates the TGF- $\beta 1 / \mathrm{Smad} 2 / 3$ signaling pathway may be a novel therapeutic for treatment of SSc.

\section{Acknowledgements}

The authors would like to thank Dr Kate Huang (The First Affiliated Hospital of Wenzhou Medical University) and Dr Jianbo Wu (The First Affiliated Hospital of Wenzhou Medical University) in the Department of Pathology for expert technical assistance and the Dr Yicheng He (Wenzhou Medical University) and Dr Zhenni Zhou (Wenzhou Medical University) for help with the mice experiments.

\section{Funding}

The present study was supported by a grant from the Wenzhou Science and Technology Bureau Project, Zhejiang Province, China (grant no. Y20140250).

\section{Availability of data and materials}

The datasets used and/or analyzed during the current study are available from the corresponding author on reasonable request.

\section{Authors' contributions}

LW and YT conceived and designed the experiments; $\mathrm{XX}$ and CD performed the animal experiments; YT, HY performed the pathological examination; $\mathrm{XH}$ analyzed the data; $\mathrm{AC}$ contributed materials and western blot analysis; XX, CD and LW wrote the paper. 


\section{Ethics approval and consent to participate}

The present study was approved by the institutional Animal Care and Use committee of Wenzhou Medical University (wydw2016-0067).

\section{Consent for publication}

Not applicable.

\section{Competing interests}

The authors have declared that they have no competing interests.

\section{References}

1. Balbir-Gurman A and Braun-Moscovici Y: Scleroderma-new aspects in pathogenesis and treatment. Best Prac Res Clin Rheumatol 26: 13-24, 2012.

2. Tyndall AJ, Bannert B, Vonk M, Airò P, Cozzi F, Carreira PE, Bancel DF, Allanore Y, Müller-Ladner U, Distler O, et al: Causes and risk factors for death in systemic sclerosis: A study from the EULAR Scleroderma Trials and Research (EUSTAR) database. Ann Rheum Dis 69: 1809-1815, 2010.

3. Bourji K, Meyer A, Chatelus E, Pincemail J, Pigatto E, Defraigne JO, Singh F, Charlier C, Geny B, Gottenberg JE, et al: High reactive oxygen species in fibrotic and nonfibrotic skin of patients with diffuse cutaneous systemic sclerosis. Free Radic Biol Med 87: 282-289, 2015.

4. Yoshizaki A, Iwata Y, Komura K, Ogawa F, Hara T, Muroi E, Takenaka M, Shimizu K, Hasegawa M, Fujimoto M, et al: CD19 regulates skin and lung fibrosis via Toll-like receptor signaling in a model of bleomycin-induced scleroderma. Am J Pathol 172: 1650-1663, 2008.

5. Allanore Y, Borderie D, Lemarechal H, Ekindjian OG and Kahan A: Acute and sustained effects of dihydropyridine-type calcium channel antagonists on oxidative stress in systemic sclerosis. Am J Med 116: 595-600, 2004.

6. Sambo P, Baroni SS, Luchetti M, Paroncini P, Dusi S, Orlandini G and Gabrielli A: Oxidative stress in scleroderma: Maintenance of scleroderma fibroblast phenotype by the constitutive up-regulation of reactive oxygen species generation through the NADPH oxidase complex pathway. Arthritis Rheum 44: 2653-2664, 2001

7. Varga J and Abraham D: Systemic sclerosis: A prototypic multisystem fibrotic disorder. J Clin Invest 117: 557-567, 2007.

8. Fernandez IE and Eickelberg O: The impact of TGF- $\beta$ on lung fibrosis: From targeting to biomarkers. Proc Am Thorac Soc 9: 111-116, 2012.

9. Liu RM and Desai LP: Reciprocal regulation of TGF- $\beta$ and reactive oxygen species: A perverse cycle for fibrosis. Redox Biol 6: 565-577, 2015.

10. Pociask DA, Sime PJ and Brody AR: Asbestos-derived reactive oxygen species activate TGF-beta1. Lab Invest 84: 1013-1023, 2004.

11. Xu L, Cui WH, Zhou WC, Li DL, Li LC, Zhao P, Mo XT, Zhang $\mathrm{Z}$ and Gao J: Activation of Wnt/beta-catenin signalling is required for TGF- $\beta / \mathrm{Smad} 2 / 3$ signalling during myofibroblast proliferation. J Cell Mol Med 21: 1545-1554, 2017.

12. Bian D, Zhang J, Wu X, Dou Y, Yang Y, Tan Q, Xia Y, Gong Z and Dai Y: Asiatic acid isolated from Centella asiatica inhibits TGF- 31 -induced collagen expression in human keloid fibroblasts via PPAR-gamma activation. Int J Biol Sci 9: 1032-1042, 2013.

13. Meng XM, Zhang Y, Huang XR, Ren GL, Li J and Lan HY: Treatment of renal fibrosis by rebalancing TGF- $\beta / \mathrm{Smad}$ signaling with the combination of asiatic acid and naringenin. Oncotarget 6: 36984-36997, 2015.

14. Si L, Xu J, Yi C, Xu X, Ma C, Yang J, Wang F, Zhang Y and Wang X: Asiatic acid attenuates the progression of left ventricular hypertrophy and heart failure induced by pressure overload by inhibiting myocardial remodeling in mice. J Cardiovasc Pharmacol 66: 558-568, 2015.

15. Xu X, Si L, Xu J, Yi C, Wang F, Gu W, Zhang Y and Wang X: Asiatic acid inhibits cardiac hypertrophy by blocking interleukin- $1 \beta$-activated nuclear factor- $\kappa \mathrm{B}$ signaling in vitro and in vivo. J Thorac Dis 7: 1787-1797, 2015.
16. Xu C, Wang W, Xu M and Zhang J: Asiatic acid ameliorates tubulointerstitial fibrosis in mice with ureteral obstruction. Exp Ther Med 6: 731-736, 2013.

17. Ramachandran V and Saravanan R: Efficacy of asiatic acid, a pentacyclic triterpene on attenuating the key enzymes activities of carbohydrate metabolism in streptozotocin-induced diabetic rats. Phytomedicine 20: 230-236, 2013.

18. Barnes J and Mayes MD: Epidemiology of systemic sclerosis: Incidence, prevalence, survival, risk factors, malignancy, and environmental triggers. Curr Opin Rheumatol 24: 165-170, 2012.

19. Highland KB and Silver RM: New developments in scleroderma interstitial lung disease. Curr Opin Rheumatol 17: 737-745, 2005.

20. Tang LX, He RH, Yang G, Tan JJ, Zhou L, Meng XM, Huang XR and Lan HY: Asiatic acid inhibits liver fibrosis by blocking TGF-beta/Smad signaling in vivo and in vitro. PLoS One 7: e31350, 2012.

21. Dong SH, Liu YW, Wei F, Tan HZ and Han ZD: Asiatic acid ameliorates pulmonary fibrosis induced by bleomycin (BLM) via suppressing pro-fibrotic and inflammatory signaling pathways. Biomed Pharmacother 89: 1297-1309, 2017.

22. Asano Y, Ihn H, Yamane K, Kubo M and Tamaki K: Impaired Smad7-Smurf-mediated negative regulation of TGF-beta signaling in scleroderma fibroblasts. J Clin Invest 113: 253-264, 2004.

23. Zhang H, Ran X, Hu CL, Qin LP, Lu Y and Peng C: Therapeutic effects of liposome-enveloped ligusticum chuanxiong essential oil on hypertrophic scars in the rabbit ear model. PLoS One 7: e31157, 2012.

24. Bei Y, Hua-Huy T, Nicco C, Duong-Quy S, Le-Dong NN, Tiev KP, Chéreau C, Batteux F and Dinh-Xuan AT: RhoA/Rho-kinase activation promotes lung fibrosis in an animal model of systemic sclerosis. Exp Lung Res 42: 44-45, 2016.

25. Servettaz A, Goulvestre C, Kavian N, Nicco C, Guilpain P, Chéreau C, Vuiblet V, Guillevin L, Mouthon L, Weill B and Batteux F: Selective oxidation of DNA topoisomerase 1 induces systemic sclerosis in the mouse. J Immunol 182: 5855-5864, 2009.

26. Servettaz A, Guilpain P, Goulvestre C, Chéreau C, Hercend C, Nicco C, Guillevin L, Weill B, Mouthon L and Batteux F: Radical oxygen species production induced by advanced oxidation protein products predicts clinical evolution and response to treatment in systemic sclerosis. Ann Rheum Dis 66: 1202-1209, 2007.

27. Blackburn RM: Too much of a good thing: Adenosine overload in adenosine-deaminase-deficient mice. Trends Pharmacol Sci 24: 66-70, 2003.

28. Kim HJ, Tashkin DP, Gjertson DW, Brown MS, Kleerup E, Chong S, Belperio JA, Roth MD, Abtin F, Elashoff R, et al: Transitions to different patterns of interstitial lung disease in scleroderma with and without treatment. Ann Rheum Dis 75: 1367-1371, 2016.

29. AdtaniPN,Narasimhan M,Punnoose AM and Kambalachenu HR: Antifibrotic effect of Centella asiatica Linn and asiatic acid on arecoline-induced fibrosis in human buccal fibroblasts. J Investig Clin Dent 8: 2017.

30. Liu J, He T, Lu Q, Shang J, Sun H and Zhang L: Asiatic acid preserves beta cell mass and mitigates hyperglycemia in streptozocin-induced diabetic rats. Diabetes Metab Res Rev 26: 448-454, 2010.

31. Sato M, Hirayama S, Lara-Guerra H, Anraku M, Waddell TK, Liu M and Keshavjee S: MMP-dependent migration of extrapulmonary myofibroblast progenitors contributing to posttransplant airway fibrosis in the lung. Am J Transplant 9: 1027-1036, 2009.

32. Wolters PJ, Collard HR and Jones KD: Pathogenesis of idiopathic pulmonary fibrosis. Annu Rev Pathol 9: 157-179, 2014.

33. Su BH, Tseng YL, Shieh GS, Chen YC, Wu P, Shiau AL and Wu CL: Over-expression of prothymosin-alpha antagonizes TGF $\beta$ signalling to promote the development of emphysema. J Pathol 238: 412-422, 2016.

34. Sato M, Muragaki Y, Saika S, Roberts AB and Ooshima A: Targeted disruption of TGF-beta1/Smad3 signaling protects against renal tubulointerstitial fibrosis induced by unilateral ureteral obstruction. J Clin Invest 112: 1486-1494, 2003.

35. Wang P, Wang Y, Nie X, Braïni C, Bai R and Chen C: Multiwall carbon nanotubes directly promote fibroblast-myofibroblast and epithelial-mesenchymal transitions through the activation of the TGF- $\beta /$ Smad signaling pathway. Small 11: 446-455, 2015.

36. Yamane K, Ihn H, Kubo M, Yazawa N, Kikuchi K, Soma Y and Tamaki K: Increased serum levels of soluble vascular cell adhesion molecule 1 and E-selectin in patients with localized scleroderma. J Am Acad Dermatol 42: 64-69, 2000. 